\title{
Exploring the Innovative Strategy of Enterprise Marketing in the Market Economy
}

\author{
Sun Haishao \\ The School of Tourism Business, Jiangsu College of Tourism, Yangzhou, Jiangsu, 225000, China
}

Keywords: Marketing management; Enterprise; Market economy; Strategy; Innovation

\begin{abstract}
In the new era of market economy, after the long-term development and exploration, marketing has become a basic market management and operation mode, which plays an important role in all aspects of the development of enterprises. The marketing is a process in which people get what they need through the exchange of value or products created by a collective or individual and ultimately, achieving win-win or win-win-win. It has become a necessary means for the development of many enterprises. In particular, with the continuous change of socialist economy, enterprises occupy a vital position in the national economy. While whether the market economy is stable or not, it has an important influence on the whole socialist process. Especially after China's accession to the WTO, the new situation and space for development have prompted Chinese enterprises to face severe challenges. In order to better adapt to and respond to the needs driven by the development of market economy, it is necessary to actively innovate the marketing strategy. Based on this, this paper will start with the analysis of the status quo of China's enterprise marketing in the new era, and further explore the innovation path of enterprise marketing in order to provide a useful reference for the better development of enterprises in the new era.
\end{abstract}

\section{Introduction}

In the course of the integration of global economy, enterprises have also been further reformed in their development. The reform and development of China's market economy system has further promoted the institutional reform of our enterprises. We have also achieved some market economic benefits in the long-term marketing development and significantly improved the market competitiveness of Chinese enterprises. Under the guidance of various marketing methods such as cultural marketing and internet marketing, we have gradually adapted to the current needs of market economy and significantly improved the adaptability of enterprises in the market economy. It is of great value for the future development of Chinese enterprises.

\section{Analysis on the current situation and problems of Chinese enterprise marketing}

\subsection{Marketing management is turning to a science}

In the current development of enterprises, in order to achieve the direct sales number growth, many enterprises gradually began to attach importance to marketing management, pay attention to enterprise staff, build a simple marketing organization structure and its corresponding sales channels, organizational systems, etc. They can also integrate their own conditions and market needs in the process of development. Choosing a variety of targeted marketing strategies, changing the past simple and traditional direct sales model, improving their marketing management and the real combination of marketing organization and system construction makes them gradually improve their own marketing management in the market competition and their own development, which promotes their continuous improvement and development.

\subsection{The marketing level of the enterprise needs to be improved}

In view of the current situation of most enterprises, they are restricted by resources in the process of development, which restricts their marketing research and development institutions, makes the 
implementation and effectiveness of marketing been greatly affected, resulting in discontinuation of marketing conditions. Judging from the corresponding level of marketing, it is clear that the level of Chinese enterprises is relatively low, the enterprises cannot follow up the investigation and follow-up analysis. This kind of problem has always been imperfectly solved, making the development of enterprises more restricted and lowering the marketing levels. In the aspect of marketing strategy innovation, compared with the enterprises in developed countries, the overall innovation level of Chinese enterprises is low. In the related research, 1070 top managers of all major industries in 63 countries of the world were selected as the research objects, and finally the top 10 most innovative companies in marketing are the world famous enterprises Apple, Google, 3M, Toyota, Microsoft, etc. And the embarrassing thing is that there is no Chinese enterprise on the list. So we should think more about the reasons for the low level of enterprise marketing and the reform point. The relatively weak marketing ability of Chinese enterprises is a problem that we must admit. According to statistics released jointly by WPP and Millward Brown, the first of the top 10 most valuable brands in the world is Apple, whose brand value has risen $67 \%$ in the past year, the second is Google, and our country has not even one entered the top ten, the top is occupied with eleventh, and Tencent Inc, Alibaba, China Mobile and others followed-up. As shown in Table 1. It can be seen that due to the generally weak marketing capabilities of Chinese enterprises, there is a lack of independent innovation status quo, while the low level of marketing is the most important reason

Table 1 The most valuable global brands in 2015 - China's list of brands

\begin{tabular}{|c|c|c|c|c|}
\hline Ranking & Brands & $\begin{array}{c}\text { Brand value (Million } \\
\text { Dollar) }\end{array}$ & industries & $\begin{array}{c}\text { Change in brand } \\
\text { value }\end{array}$ \\
\hline 11 & Tencent & 76,572 & Technology & $43 \%$ \\
\hline 13 & Alibaba & 66,375 & Retail & new \\
\hline 15 & China Mobile & 59,895 & Telecommunication & $20 \%$ \\
\hline 21 & Baidu & 40,041 & Technology & $35 \%$ \\
\hline 22 & ICBC & 38,808 & Bank & $-8 \%$ \\
\hline 41 & CCB & 22,065 & Bank & $-12 \%$ \\
\hline 50 & $\mathrm{ABC}$ & 20,188 & Bank & $11 \%$ \\
\hline 62 & CLIC & 17,365 & Insurance & $44 \%$ \\
\hline 63 & SINOPEC & 17,267 & gas and petroleum & $21 \%$ \\
\hline 65 & BOC & 16,438 & Bank & $16 \%$ \\
\hline 68 & $\begin{array}{l}\text { PING AN OF } \\
\text { CHINA }\end{array}$ & 15,959 & Insurance & $29 \%$ \\
\hline 70 & HUAWEI & 15,335 & Technology & new \\
\hline 71 & PetroChina & 15,022 & gas and petroleum & $21 \%$ \\
\hline 99 & $\begin{array}{l}\text { China } \\
\text { Telecom }\end{array}$ & 11,075 & Telecommunication & new \\
\hline
\end{tabular}

Note: this data is published jointly by WPP and Millward Brown.

\subsection{Poor marketing concept of enterprises}

In the process of marketing, based on the poor marketing idea led to the marketing effect is not high. The current enterprises are facing a major problem. The concrete analysis shows that the enterprise lacks the marketing skills and does not have the scientific marketing strategy guidance, In this way, in the progress of the marketing work, it often appears that the marketing morality is low and so on. The bad marketing phenomenon and even the loopholes are more common. Causing the marketing crisis of its enterprises. With the lack of corresponding management and control measures, it is impossible to strictly supervise the marketing operation process of enterprises, resulting in a sudden drop in marketing effect, which is not conducive to the better development of enterprises. 


\section{The innovation strategy of enterprise marketing in the market economy}

\subsection{Commodity marketing strategy}

In the traditional market development, we need to increase the inventory of goods, so as to effectively meet the needs of the vast number of consumers. Relatively speaking, the inventory cost is relatively high, and it is also easy to generate the phenomenon of cargo loading, which leads to economic losses. For small and medium-sized enterprises, they cannot bear the pressure, which leads to bankruptcy. Under the environment of e-commerce development, the cost inventory of enterprises is reduced. For small and medium-sized enterprises, it can reduce the cost of development and retain funds for other economic activities. At the same time, e-commerce marketing mode provides a platform for the vast number of consumers and businesses to communicate with each other, helps consumers understand the actual situation of goods and manufacturers, and also helps merchants understand the actual needs of consumers, thereby significantly improving the feasibility of transactions. Only in this way can we meet the needs of the customers better and realize the optimal design and production of the products. For a long time, after receiving the approval of the customer, it has laid the marketing foundation of the business in the development of the enterprise. This development model can not only promote the marketing of enterprise products, but also stabilize the position of the enterprise market, and help to promote the healthy development of the enterprise.

\subsection{Management of workers}

In the development of new environment, the development mode of e-commerce has significantly reformed the way of marketing management of traditional enterprises. The most obvious point is that the number of workers in enterprises has been significantly reduced. Under the traditional marketing management mode, it is necessary to set someone in charge of each environment. The development model of $\mathrm{E}$ - commerce does not need to be like that. It reduces the number of workers, at the same time it is also less related to the network marketing link, and promotes the simple development of the enterprise marketing model. In the environment of e-commerce development, enterprises can meet the needs of the current marketing development as long as they can increase the training of professional talents. Especially in the development of Taobao business, this is more obvious. Even if only one person can realize the effective operation of a store, it can effectively promote the development of e-business network marketing. At the same time e-commerce network marketing will also become the main mode in the future.

\subsection{The discovery and training of electronic business talents in Enterprises}

In the development process of e-business network marketing, enterprises have great demand for e-business talents. At the same time, it is required that these talents have a certain practical operational ability. But at present, talents are scarce. In view of this situation, we should strengthen the practice ability of e-commerce talents, and thus effectively promote the healthy development of the enterprises. For the current status analysis, e-commerce coverage is more extensive. Whether in the economy or finance, or in the computer application and the related software development process, it is not only necessary for the e-commerce talents to have rich theoretical knowledge, but also to improve their knowledge application ability, improve their hands-on ability and be active Promote their own websites, increase the economic benefits gained on the websites, and promote the development of e-commerce. Meanwhile, in the process of enterprise development, business managers must also clearly realize that in talent training time is relatively long, and we must start from the foundation. More haste, less speed, it is also necessary to combine the actual needs of the enterprises with the actual needs of the enterprises, and on the basis of meeting the actual needs of the enterprises, the training of the talents should be carried out. To be able to significantly show the characteristics of e-commerce talents. Business managers should recognize the important role of business people. These people significantly reduce the cost of enterprises in the development of enterprises, and lay the foundation for the healthy development of the enterprises. In the process of actual operation and development, it is necessary to strengthen the network promotion. It also needs 
to be gradually improved for the website running backstage. On the one hand, we should effectively improve sales volume, and on the other hand, we should also focus on building good relations with customers and maximizing the trust of customers, so that managers can put more energy into their store operation, optimize personnel management and promote the healthy development of enterprises. In short, under the circumstance of e-commerce development, e-commerce talents are the focus of enterprise marketing and development. Meanwhile, they can also significantly improve the economic benefits of enterprises and maximize the profits of enterprises. Strengthening e-commerce talents cultivation can better promote the development of enterprises in the information environment of e-commerce [4-6].

\subsection{Making a scientific and reasonable marketing model}

In the analysis of the rationality and effectiveness of the current marketing mode, we find that marketing mode can not only promote the marketing development of enterprise products, but also guide enterprises to achieve better economic benefits. In the process of the above analysis, it also needs to realize the innovation and development of the enterprise marketing, and raise it to the spirit level of the enterprise. On the one hand, the quality management of enterprises should be strengthened, and the market environment needs to be accurately positioned. But if we want to make a reasonable marketing model, we must have a certain guarantee for all aspects of the enterprise, and also combine with the development of the times. In the current social development process, most of their own space has been expanded to some extent, consumers' demands have also shown a certain degree of personalized development, especially young customers in the purchase of goods to reflect their own personality characteristics, for almost no personalized products they are almost not interested. Therefore, in the formulation of enterprise marketing mode, the corresponding marketing mode should be formulated according to the changes of current consumer demand. In the environment of e-business marketing, marketing strategy is also called "personalized" marketing. In the current marketing development of clothing industry, personalized marketing has begun to be applied actively. In the process of clothing brand marketing, some brands have realized the docking of specific design parts and product sales, so as to better meet the needs of the majority of consumers.

\section{Conclusions}

In summary, in the current enterprise development, the scientific enterprise marketing strategy is the motive force of the enterprise development, and also the key point. At present, in the development of enterprises, we must pay enough attention to marketing strategies, and actively improve the problems that enterprises appear in the development of marketing, so as to effectively improve our competitiveness in the market, so as to achieve the sustainable development of enterprises.

\section{References}

[1] Hu Zhiying. Research on network marketing in the context of e-commerce[J]. Journal of Jiamusi Education Institute,2017, (8):459.

[2] Liu Jing. Exploration of Xinyang Maojian electronic commerce marketing development approach[J]. Tea in Fujian, 2016, (10):61-62.

[3] Chen Dong. Research on marketing plan based on e-commerce environment[J]. CHINA Journal of Commerce,2017, (11):11-12.

[4] Hu Xudong. Research on the training mode of marketing talents in Higher Vocational Colleges under the background of electronic commerce[J]. Value Engineering,2017, (33):182-183.

[5] Liu Chang. Research on the new strategy of marketing in the era of E-business[J]. Information Recording Material,2018, (1):60-61.

[6] Hu Xudong. Research on marketing strategy innovation based on e-commerce background[J]. DianZiShangWu,2017, (9):42-43. 